WHY ARE THE LIGHTS SO DIM?

INSTITUTIONS EDUCATING THE PUBLIC ON PHOTOGRAPHIC PRESERVATION

\author{
By \\ Suman K. Guram \\ BA, Anthropology, University of Windsor, 2011
}

A thesis presented to
Ryerson University
and
George Eastman House
in partial fulfillment of the degree requirements of

Master of Arts in the Program

of

Photographic Preservation and Collections Management

Toronto, Ontario, Canada, 2013

(C) Suman K. Guram, 2013 


\section{Author's Declaration for Electronic Submission of a Thesis}

I hereby declare that I am the sole author of this thesis. This is a true copy of the thesis, including any required final revisions, as accepted by my examiners.

I authorize Ryerson University to lend this thesis to other institutions or individuals for the purpose of scholarly research.

I further authorize Ryerson University to reproduce this thesis by photocopying or by other means, in total or in part, at the request of other institutions or individuals for the purpose of scholarly research.

I understand that my thesis may be made electronically available to the public.

Suman K. Guram 


\title{
Why are the Lights so Dim? Institutions Educating the Public on Photographic Preservation
}

\author{
Master of Arts 2013 \\ Suman K. Guram \\ Photographic Preservation and Collections Management \\ Ryerson University and George Eastman House
}

\begin{abstract}
With the emergence and expansion of the field of Photographic Preservation, it is important and beneficial to explain preservation initiatives on display to the audiences that we are engaging and preserving for. This assists in facilitating a public understanding of photographic preservation, as well as building relevance to the institution's collections and mission. This project is concerned with the role interpretation plays in the visitor's experience, specifically through text labels and seeks to gain insight into the ways museums educate their audiences about the special care required to exhibit photography. This data was collected by conducting a series of interviews with various institutions, as well as conversations with professionals in the field. Using these findings and appropriate research, four piece labels were created that would accompany and explain four differing preservation strategies in exhibitions: facsimile prints, timed light boxes, the use of drapery and low light levels.
\end{abstract}




\section{ACKNOWLEDGEMENTS}

This project would not have been possible without the support of many people. Firstly, I cannot thank my family enough for their endless and loving support throughout my academic endeavours and life journey. Thank you for standing behind me with moral encouragement and humour and for setting a good example. I would not have been able to achieve this success without you.

I also thank my first reader Jessica Johnston, whose continued interest in my research and positive encouragement made this project possible. I would also like to extend thanks to Roger Bruce for taking the time to assess my thesis as my second reader.

Thank you to the faculty of the Master of Arts in Photographic Preservation and Collections Management program at Ryerson University and George Eastman House for educating, mentoring and inspiring me throughout the duration of graduate school. I am particularly thankful for the support and guidance from Alison Nordström who allowed me to embrace my area of interest and the delightfulness associated with independent research.

I offer a special thank you to all my friends for their support throughout my graduate career and my thesis, especially Naziha Hamde. Without your positive motivation, confidence in my success and our enlightening conversations, it would have been very difficult to achieve my goals with such optimism and passion. Thank you! 
This thesis is lovingly dedicated to my mother Sarbjit Guram, whose infinite support and belief in me has contributed to my continued success and has allowed me to grow into the woman she knew I would be. I love you. 


\section{Table of Contents}

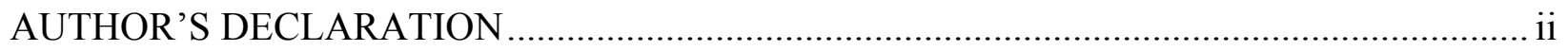

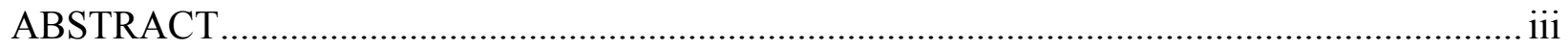

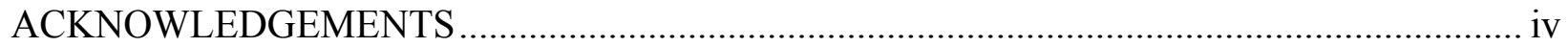

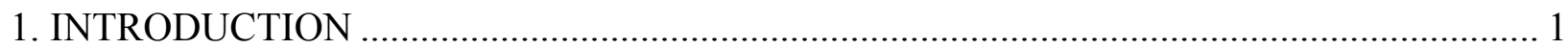

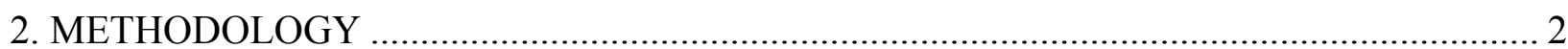

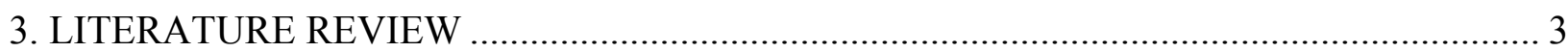

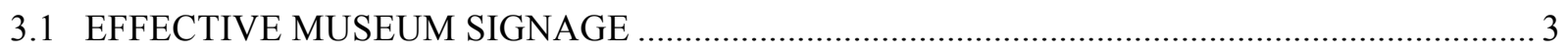

3.2 PRESERVATION CONCERNS DURING EXHIBITION …………………………………....... 6

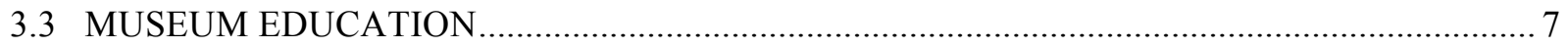

4. MUSEUM EDUCATION AND SIGNAGE

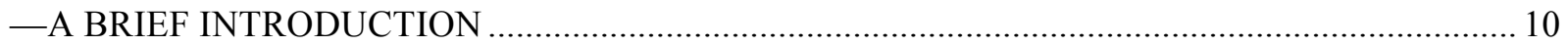

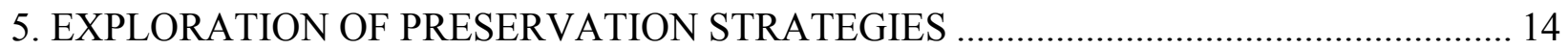

6. SURVEY OF BEST PRACTICE IN INTERPRETIVE MUSEUM SIGNAGE PERTAINING

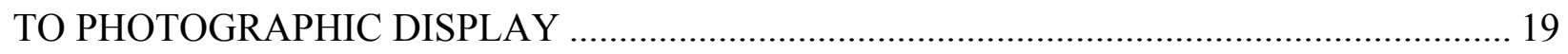

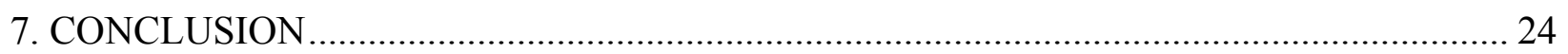

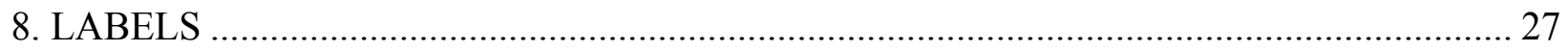

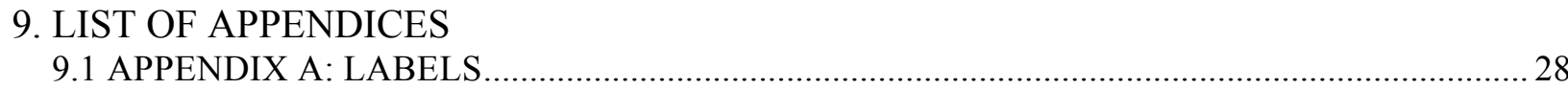

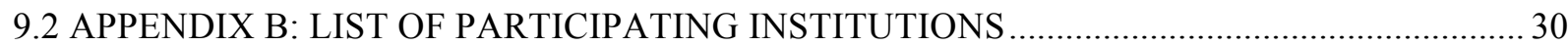

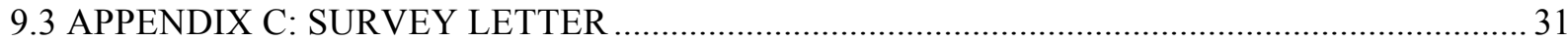

9.4 APPENDIX D: LIST OF ILLUSTRATIONS ……………………………………………......... 33

9.5 APPENDIX E: EXAMPLES OF LABELS USED IN CURRENT PRACTICE ………………….... 38

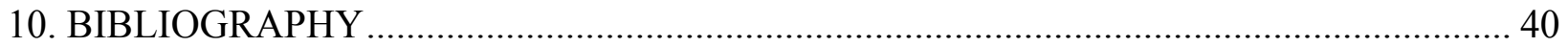




\section{Introduction}

This project is aimed at investigating interpretive text labels used to explain photographic preservation strategies employed in museum and gallery exhibitions. Specifically, this project examines museum interpretation strategies and the employment of museum signage to explain four primary areas of photographic preservation practiced in mounting museum and gallery exhibitions, and will offer recommendations for standardized labels for each of the following strategies: the use of timed light boxes; the use of drapery or textile coverings; the use of facsimiles; and, the maintenance of low light levels throughout exhibition spaces. This research is being undertaken to better understand the process and role of photographic preservation in mounting museum and gallery exhibitions, while also playing an important role in disseminating knowledge about the importance of photographic preservation work amongst a broad public. Explaining such things as why the lights are so low or why an object is behind a curtain assists institutions in enhancing visitor experiences while building relevance and interest in the collections under their care.

Although extensive research has been conducted on exhibition signage, there is no research that currently exists pertaining specifically to exhibition labels that explain photographic preservation strategies used in exhibitions. Further, there are no examples of standardized interpretive texts explaining these important aspects of preservation to audiences. As a result, the investigation of current practices related to creating interpretive texts, rich with preservation insights, as well as the creation of standardized labels would be a valuable resource to the field of photographic preservation and the public it serves. 


\section{Methodology}

This investigation relates to several fields of museum and gallery work, therefore a multifaceted research strategy was employed. A review of literature specific to museum signage and preservation strategies used in mounting exhibitions and facilitating museum education played prominently into this project. Specifically, the emphasis of the survey of literature includes how interpretive labels have been used in the past, what they aim to explain, and suggestions for best practice. Additionally, it includes examining the environmental conditions specialists take into consideration when planning an exhibition. These include such things as lighting levels in galleries, temperature and humidity control, security, and the handling of objects by staff during the implementation and transport phases. Lastly, this survey examines the role and purpose of education in museums, and perhaps more importantly exhibitions. By analyzing and summarizing relevant literature it was possible to determine general best practices for creating effective labels. Further, examples of current preservation strategies explained within exhibitions were obtained by interviewing colleagues and professionals in the field. Interviews were conducted using a short survey of questions distributed to curators, assistant curators, a registrar, a collections manager, and a director of exhibitions and design. In addition to this, members of staff at George Eastman House International Museum of Photography and Film, the Art Gallery of Ontario, and Ryerson University (including Alison Nordstrom, Jessica Johnston, Marta Braun, Maia Sutnik, and Sophie Hackett) offered suggestions and advice. A total number of seventeen institutions (Appendix B) were contacted, with their justification for inclusion in this project depending on their institutional history of exhibiting photography, as 
well as the size of their photographic collection. This study was limited to museums and institutions in the United States as a way to control and regulate parameters.

\section{Survey of Literature}

As paths of differing investigation, there has been extensive research conducted pertaining to effective museum signage, preservation concerns in exhibitions, and the historic and contemporary role of education in museums; however, there has been no exploration, and in fact a gap in discourse, examining the various ways in which museums use interpretive text labels to explain preservation strategies for photographs on display in museum and gallery exhibitions. The majority of literature pertaining to museum signage describes physical attributes of the label, as well as legibility and targeted audience types. Moreover, publications regarding preventive preservation focus entirely on concerns within the exhibition environment and literature on the topic of museum education usually only addresses its historic role. Surprisingly, there has not been further research linking preventive preservation methods utilized in exhibitions, to the strategic employment of informative museum signage offering insights about preservation work, and the role that education plays in educating and building understanding about preservation processes amongst the public. As a result, my research into this topic is threefold, and investigates the following: effective museum signage, preservation concerns in exhibitions, and the role of education in museums.

\section{Effective Museum Signage}

According to a recent survey of literature, effective museum signage entails standards for legibility such as the physical characteristics of the label itself. Three primary publications make reference to this including: The Standards Manual for Signs and Labels (1995), published by the 
American Association of Museums; Beverly Serrell's, Making Exhibit Labels: A Step-by-Step Guide (1983); and, Exhibit Labels: An Interpretive Approach (1996), also by Beverly Serrell. These publications support my argument as they set forth varied institutional frameworks for best practices in the preparation of exhibiting labels. Proposed in The Standards Manual for Signs and Labels are eight basic elements that form the basis for legibility in labels and signs, including: type size, typeface, character proportion, letter and line spacing, colour, contrast, medium, installation, and lighting. ${ }^{1}$ The American Association of Museums articulates, "An accessible label or sign is one that can be read and understood by the viewer." ${ }^{2}$ This is an important point to mention as it highlights that every visitor will read and understand a label differently. As a result, it is essential to create a label that employs a universal language and appearance. Along with standards for legibility, Serrell also discusses the planning, composition, and production of labels and signage in Making Exhibit Labels: A Step-by-Step Guide. This book provides useful detailed insight into attaining label objectives and how to write a label effectively. In her second book, Serrell highlights the importance of interpretive labels and defines them as "Any label that serves to explain, guide, question, inform, or provoke—in a way that invites participation by the reader." ${ }^{3}$ This demonstrates that exhibition labels are useful because they aim to educate through the use of text, requiring the visitor to participate by engaging in their written dialogue.

As examined in several publications, effective museum signage forms an important link between object and viewer. Three publications make reference to this including, Exhibitions in

\footnotetext{
${ }^{1}$ Standards Manual for Signs and Labels. (Washington, DC: American Association of Museums and the Metropolitan Museum of Art, 1995),13.

${ }^{2}$ Ibid, 8 .

${ }^{3}$ Serrell, Beverly. Exhibit Labels: An Interpretive Approach. (Walnut Creek: AltaMira Press, 1996), 9.
} 
Museums (1991) by Michael Belcher, The Museum Experience (1992) by John Falk and Lynn Dierking, and Tom Klobe's Exhibitions: Concept, Planning and Design (2012). Belcher discusses best practices for communication through exhibitions and labels, as well as reiterating the fact that exhibition labels form a link between the object and viewer ${ }^{4}$. He is concerned with how meaningful and memorable a museum trip will be to a visitor before, during, and after their visit. Although this publication is primarily concerned with visitor pathways and whether or not labels are read, Falk and Dierking make an important point when they say, "Even though the visitor's physical context can include a multitude of events or features, it is generally assumed that objects and labels have the greatest influence on the visitor's museum experience. ${ }^{, 5}$ Klobe's publication is concerned with the various facets and decision-making associated with planning an exhibition. Included is a section devoted to labels, where Klobe discusses that because a large portion of a museum's audience visits the institution at varied times and rates, labels are the primary means of communication between visitor, object and the institution. ${ }^{6}$

Two primary publications offer guidance on how to write effective labels for various audiences including, Text in the Exhibition Medium (1995) edited by Andrée Blais, and Barry and Gail Dexter Lord's The Manual of Museum Exhibitions (2000). Both publications are intended for use by museum practitioners and provide practical advice on the presentation of text in the museum environment. Both examine at length the various ways in which text plays a key role in the museum experience, such as motivating visitors to read labels, reading strategies used

\footnotetext{
${ }^{4}$ Belcher, Michael. Exhibitions in Museums. (London: Leicester University Press, 1991), 58. ${ }^{5}$ Lynn D. Dierking, and John H. Falk, The Museum Experience, (Washington, DC: Whalesback Books, 1992), 67.

${ }^{6}$ Klobe, Tom. Exhibitions: Concept, Planning and Design. (Washington, DC: The AAM Press of the American Association of Museums, 2012), 52.
} 
by various audience types, and considerations for utilizing oral communication compared to written text.

\section{Preservation Concerns During Exhibition}

There has been an abundance of literature written on environmental concerns in exhibitions, however, the most useful publications for this study include Susan Corr's Caring for Collections: A Manual of Preventive Conservation (2000), Michael Brawne's The Museum Interior: Temporary and Permanent Display Techniques (1982), the International Institute for Conservation's Preventive Conservation: Practice, Theory and Research (1994), and Susan Keene's Managing Conservation in Museums (2002). Corr assigns a whole chapter to environmental conditions and how they affect the collection. In his book, Brawne has assigned a chapter to the preservation environment discussing common concerns and mentions that the effect of temperature and humidity is far less pervasive than damage caused by exposure to light. Keene's publication covers a wide range of areas as they pertain to preservation, including discussions about collections, visitors, management planning, and digitization to name a few. Keene's insights assist in planning for preservation, such as offering insights about the cost of environmental monitoring equipment to provide an example.

Few publications have been written on the preservation concerns associated with storage and transport of archival materials. These include Conservation and Exhibitions: Packing, Transport, Storage and Environmental Considerations (1987) by Nathan Stolow, Preventive Conservation in Museums (1995) by the Canadian Conservation Institute, and Chris Caple's, Conservation Skills: Judgment, Method and Decision Making (2002). Conservation consultant Stolow's publication aligns itself with my research as it focuses specifically on the development of controlled environments for the travel and movement of works of art during an exhibition, 
while taking into account preservation concerns. He mentions, "Works of art and objects can deteriorate further while in storage or on exhibition as a result of environmental action, even when adequate collection management procedures are in force..." ${ }^{77}$ In addition to highlighting environmental considerations, Preventive Conservation in Museums discusses at length storage and protecting objects on display, disaster planning, and the handling and care of objects. Conservation Skills offers advice on how to make responsible decisions regarding conservation.

An area of preservation concern often overlooked in scholarly literature concerns the chemical makeup and deterioration associated with various types of objects. The Alaska State Museum's publication Wise Guide (2000) and A Practical Guide to the Conservation and Care of Collections (1998) edited by D. Gilroy and I. Godfrey discuss precisely this. Wise Guide is particularly useful in my research due to its inclusion of a section on black \& white and colour photography, in which major causes of deterioration are discussed and recommendations on safe storage are provided. The other publication, A Practical Guide to the Conservation and Care of Collections, was beneficial to my research as it included a chapter on photographs, where overviews of photographic processes and explanations of their chemical makeup and deterioration is provided.

\section{Museum Education}

The educational roles museums undertake and their mandate obligations are reflected in in two publications, Excellence in Practice: Museum Education Standards and Principles (2002) and Excellence and Equity: Education and the Public Dimension of Museums (1990). Both

7 Stolow, Nathan. Conservation and Exhibitions: Packing, Transport, Storage and Environmental Considerations. (London: Butterworth \& Co., 1987), 5, 
publications help guide and inform the practice of museum education. ${ }^{8}$ Excellence and Equity tends to focus more on an expanded definition of museums' educational goals and is the first major report on the role of education in museums to ever be issued by the American Association of Museums. Excellence in Practice is a document written in 1990 that was restructured in 2002 with updated information regarding key concepts and standards concerning education in museums. Graeme Talboys' book, Museum Educator's Handbook (2000) was useful to my research as it dedicates a chapter to the educational role of museums. Talboys mentions, "By recognizing education as their reason for being, museums not only return to the purpose for which they were first created, but also firmly establish themselves in a role that is essential to the future of society." National Standards \& Best Practices for U.S. Museums (2008) is the most recent publication designating two separate chapters to the standards regarding institutional mission statements and education and interpretation. Each presents us with a list of characteristics of excellence that museums should possess in order to fulfill their basic obligations in that area of operation. ${ }^{10}$ One publication dedicated entirely to the visitor's experience and visitor studies is A Companion to Museum Studies (2006), edited by Sharon Macdonald. Macdonald engages in discourse about the multiple facets of visitor studies from the history of incorporating visitor-focused environments to studies evaluating the visitor's experience. In a separate publication, Eilean Hooper-Greenhill provides us with a definition of the term in her essay titled, Studying Visitors (2007). “'Visitor Studies' is an umbrella term for a

${ }^{8}$ Excellence in Practice: Museum Education Standards and Principles, Developed by the Committee on Education (EdCom), American Association of Museums, 1.

${ }^{9}$ Graeme K. Talboys, Museum Educator's Handbook, (Hampshire: Gower Publishing Limited, 2000), 8.

${ }^{10}$ National Standards \& Best Practices for U.S. Museums. Washington, DC: American Association of Museums, 2008, 59. 
range of different forms of research and evaluation involving museums and their actual, potential, and virtual visitors which collectively might be termed the 'audience' for museums.",11

The history of museum education is the focus of Hooper-Greenhill's publication, and of Edward and Mary Alexander's. While Museums and the Shaping of Knowledge (1992) provides a general history of educational initiatives in museums, Museums in Motion (2008) tends to focus more on how the concept of education prevailed in the exhibition space. For example, Alexander and Alexander state that the specialized type of education used by docents can be referred to as interpretation or the use of original museum objects to implement learning that emotionally engages the visitor through oral communication. ${ }^{12}$ In a concluding statement, the Alexander's mention, “Exhibition, education, or interpretation — the conveyance of culture — and a commitment to community or social welfare have grown to be important aims for the museum in the last century." 13 This directly relates to my research as it highlights that public education and an obligation to visitors has historically been a main objective for institutions. The goals of this project include aiming to educate an audience about photographic preservation through the use of interpretive text.

The publications mentioned in this survey are mostly concerned with museum signage as a broad subject area, methods on how to effectively plan exhibitions from a conservation standpoint, and on how to re-establish museum standards in regards to environmental considerations within the presentation space. Literature has also taken into consideration the standards aligned with educational mandates and purposes. However, there has been no prior

\footnotetext{
${ }^{11}$ A Companion to Museum Studies, ed. Sharon Macdonald (Malden: Blackwell Publishing, 2006), 363.

${ }^{12}$ Alexander, Edward P., and Mary Alexander. Museums in Motion: An Introduction to the History and Functions of Museums. Lanham: AltaMira Press, 2008, 7.

${ }^{13}$ Ibid, 10.
} 
literature written linking all these areas of exploration together as in the research being undertaken for this project: educating the public on photographic preservation strategies as exemplified in interpretive labels in exhibitions. Research in related areas has made this study possible and has allowed for the exploration of this aspect of photographic preservation in another light.

\section{Museum Education and Signage}

\section{A Brief Introduction}

Examining the role of education is critical to this project as communication and the facilitation of learning are the primary concerns of interpretive text labels. Due to a variety of factors such as advances in technology, visitor experiences and evolving mandates, many museums have embraced transparency as a learning tool, which changes the face of exhibitions, interpretation and education strategies. ${ }^{14}$ Further, because museum audiences tend to come from varied professional and academic backgrounds, it is important to consider what previous knowledge they bring when it comes to shaping their museum and gallery-going experiences. ${ }^{15}$ Consequently, it is the responsibility of the museum and its professionals to devise strategic and effective ways to inform a broad and diverse public of its resources and activities. An industry standard mentioned by Elizabeth Merritt in the chapter, Standards Regarding Education and Interpretation, in National Standards \& Best Practices for U.S. Museums is, that "the museum uses techniques, technologies and methods appropriate to its educational goals, content,

\footnotetext{
${ }^{14}$ Alexander, Edward P., and Mary Alexander. Museums in Motion: An Introduction to the History and Functions of Museums. Lanham: AltaMira Press, 2008, 10.

${ }^{15}$ Lord, Barry, and Gail Dexter Lord, ed. The Manual of Museum Exhibitions. Walnut Creek, CA: AltaMira Press, 2000, 373
} 
audiences and resources." ${ }^{, 16}$ This is useful to this project because it emphasizes the point that museums should take the appropriate actions to share their knowledge and resources with the public. This facilitates a positive learning environment and as a result, allows institutions to fulfill a part of their educational mandate. By disseminating knowledge of the care of photographs by exhibiting them in appropriate housing and explaining this through the use of interpretive text would assist in attaining an educational goal. It is also important to consider that the museum acknowledges the needs and characteristics of its existing and prospective audiences and uses this knowledge to inform its interpretation. This means employing an effective educational plan (inclusive of interpretive text labels) that aims to educate and communicate with the museum's specified visitor audience, while taking into consideration their professional or academic backgrounds, varied interests and possible disabilities.

Museum education and signage also play prominently into shaping the visitor experience. The visitor experience can be strategically shaped to ensure a broad range of audience types engage meaningfully and positively with museum and gallery content. Providing an explanation as to why photographic preservation strategies are utilized in exhibitions holds the potential to add meaningful layers of understanding about works on display, the collection as a whole, and museum and preservation work more broadly. Museums engage broad audiences and as a result, they need to devise strategies for communicating to several audience types, to facilitate various connections to the works and institution.

In addition to describing and interpreting objects on display, museum signage is sometimes used to explain a number of aspects of an institution's environment. For example, The

${ }^{16}$ National Standards \& Best Practices for U.S. Museums. Washington, DC: American Association of Museums, 2008, 59 
Standards Manual for Signs and Labels and its study of the Metropolitan Museum of Art declares that there are three main label categories targeted towards visitors, including: orientation signs that identify public amenities and basic museum information, such as restrooms and stairways ${ }^{17}$; directional signs to assist visitors with orientation of the museum as exemplified in gallery names and exhibition titles; and finally, gallery signs and labels to inform visitors about works of art on view, such as introductory and text panels which can be seen on walls, in cases, and on floor areas. ${ }^{18}$ Beverly Serrell expands on the idea that museums and galleries make use of categories when devising signage in Making Exhibit Labels she mentions that specimen identification labels include information that is unique to each object such as date, origin, catalogue number and donor name. ${ }^{19}$ Commonly, these label categories assist visitors' engagement with the museum and its objects, however, there are also labels that state what is unconventional and unacceptable behaviour within the gallery space. For example, many exhibition environments have signage stating in words or graphics "No Smoking" or "No Food or Drink Allowed". However, there is not typically any explanation as to why a visitor should not smoke in the museum or why they should not have food or beverages in gallery spaces. Findings from the survey mentioned above indicate that the supplementary information that is provided on labels is important and beneficial because it facilitates learning and relevance building. For example, a label that reads "Do Not Touch" is less effective than a label that reads, "Do not touch because touching may harm or damage the objects on display."

${ }^{17}$ Standards Manual for Signs and Labels. (Washington, DC: American Association of Museums and the Metropolitan Museum of Art, 1995), 8.

${ }^{18} \mathrm{Ibid}, 8$.

${ }^{19}$ Serrell, Beverly. Making Exhibit Labels: A Step-by-Step Guide. (Nashville: American Association for State and Local History, 1983), 12. 
The exhibition environment is important when considering the care and preservation of photographs and it is also the junction where preservation strategies, visitor experiences and interpretation coincide. The exhibition and gallery space is important because it is at this point where objects are released from their climate and light managed environments, protective housings, and secure safeguarded vaults into display areas where these crucial facets of preservation are hard to maintain and control. Preservation issues of concern to exhibition and photographic specialists include light management, temperature and humidity control, object security, and the handling, packing, transport, and storage of archival materials. In his publication Tom Klobe asserts, “...environmental factors such as light and fluctuations in temperature and humidity can cause damage. Designers must be conversant with conservation concerns that include material and finish selection, case construction, lighting design, and display mounts. ${ }^{, 20}$ Simplifying this information through the use of interpretive labeling is an effective strategy to communicate preservation concerns. An educational agenda and programming can strategically direct educational initiatives about preservation to include labeling that explains these concerns to visitors. Klobe further goes on to proclaim that the conservation needs of objects on display must be individually catered to when considering lighting an exhibition. ${ }^{21}$ Although damage to an object incurred by light is of major concern to photographic specialists, another area of worry is humidity. As stated by Michael Brawne in The Museum Interior: Temporary and Permanent Display Techniques, "the greatest threat from these environmental considerations comes from excessive humidity, which causes mould growth, metal corrosion and some chemical reactions in paper and textiles as well as extreme dryness,

${ }^{21}$ Klobe, Tom. Exhibitions: Concept, Planning and Design. (Washington, DC: The AAM Press of the American Association of Museums, 2012), 34. 
which is often a result of heating, producing shrinkage and brittleness." ${ }^{22}$ Only a small percentage of visitors have an understanding of the damage caused to photographs by humidity, so implementing an interpretive plan to explain this to visitors would assist them in building relevance and making connections to collections material. Lastly, Nathan Stolow makes an interesting point in Conservation and Exhibitions: Packing, Transport, Storage and Environmental Considerations, stating that "works of art and objects can deteriorate further while in storage or on exhibition as a result of environmental action, even when adequate collection management procedures are in force. Those works of art composed of cellulose, textile fibres, paint, metal, animal tissues, or organic binders are susceptible in various ways to chemical or physical alteration through the action of oxygen, humidity, atmospheric pollutants, or light.."23 The exhibition and gallery environment is a distinctive setting in that it aims to teach through the use of collections material and textual narratives. It then uses these textual descriptions to educate an audience. With the many types of signage that can be found in an exhibition and gallery space, it is crucial to include ones that explain preservation concerns that result from objects being on display. This will allow a museum to engage its audience with the special care required to exhibit photography, as well as contributing to the museum's long-term preservation plan.

\section{Exploration of Preservation Strategies}

In the past, timed light boxes have been used to exhibit photographs that are particularly light sensitive. Light exposure is detrimental to the life of most nineteenth century photographs,

\footnotetext{
22 Ibid, 120.

${ }^{23}$ Stolow, Nathan. Conservation and Exhibitions: Packing, Transport, Storage and Environmental Considerations. (London: Butterworth \& Co., 1987), 5,
} 
chromogenic process prints, instant process colour and dye-transfer prints, and some gelatin silver prints. ${ }^{24}$ As a result, when exhibiting such prints, it is a good idea to expose them to as little light as possible. Each time a visitor pushes the button on the timed light box, it disperses an appropriate amount of light for a minimum amount of time. This will highly decrease the damaging effects caused by exposure to light, ultimately increasing the existence of the photograph or object. Timed light boxes are important tools for inclusion in museum and gallery exhibitions due to the fact that they support preservation initiatives, while also facilitating interactive engagement. The timed light box engages the visitor as it attracts him or her to its unique appearance. Interpretive text highlighting why this preservation method is implemented is an important instance to communicate with an audience as it assists in not only building relevance and knowledge sharing amongst its public, but it helps mould a meaningful experience.

Using responses from the survey (Appendix C) that was distributed to various institutions (Appendix B), examples of the effective use of timed light boxes in museum and gallery exhibitions can be found for showcasing by The Phillips Collection, and at the George Eastman House International Museum of Photography and Film. The Phillips Collection arranged to have the traveling exhibition Truth Beauty: Pictorialism and the Photograph as Art shown in their gallery space. Interpretive text labels in this exhibition explain why a photographic object was displayed as a facsimile in a timed light box. However, because this exhibition was on loan from George Eastman House, it was this museum that generated the didactic text. Further, when George Eastman House exhibited this collection of photographs, it also used timed light boxes to display facsimile autochromes by Edward Steichen. George Eastman House also used timed light

\footnotetext{
${ }^{24}$ Lavedrine, Bertrand. Photographs of the Past: Process and Preservation. Los Angeles: The Getty Conservation Institute, 2007. 296
} 
boxes to exhibit reproductions of autochromes for another exhibition Where We Live. However, in this last instance, the light remained lit throughout the exhibition.

In some instances, photographs have reached their limits to remain stable. Repeated use and extended exposure to light results in limited access and display of a particular photograph. In cases such as this, surrogates or facsimiles should be substituted for the original photograph. ${ }^{25}$ Facsimiles are unique in that they are virtually accurate reproductions of original photographic works. ${ }^{26}$ This not only allows for the original print to be housed safely in storage making preservation a priority, but it also facilitates greater access to collections, strengthening the overall visitor experience. As a result, an understanding and clarification of this concept to the public would be beneficial in explaining museum processes and building much needed relevance amongst a diversifying public.

The preservation initiative of utilizing high quality and visually accurate reproductions can be seen at the George Eastman House, the Cleveland Museum of Art, Nelson-Atkins Museum of Art, and the Metropolitan Museum of Art amongst many others that are now embracing the practice. When George Eastman House exhibits facsimile prints, they provide text explaining this preservation medium. The label highlights that the original print has been replaced with a facsimile to ensure that additional exposure to light will not damage the print (Appendix E). The Cleveland Museum of Art explains that even if a print is on display in controlled lighting conditions, that damage from light is still a potential threat (Appendix E). Due to this, the original was replaced with a facsimile. The Nelson-Atkins Museum of Art uses text to explain why facsimiles are used in exhibitions, but only rarely. This museum has displayed

\footnotetext{
${ }^{25}$ Ibid, 296

${ }^{26}$ Stocks, Bronwyn. "The Facsimile and the Manuscript." The University of Melbourne , 2007. http://www.unimelb.edu.au/culturalcollections/exhibitions/facsimile/essay.html.
} 
facsimiles of autochrome plates, but not for photographic prints. Lastly, the Metropolitan Museum of Art does exhibit facsimile prints and states this in the pertinent label, but there may not necessarily be an explanation as to why a facsimile is being shown over the original work.

Light management and light levels in exhibitions are critical to the longevity of photographs, whether they are fragile or not. Exposure not only causes fading of a photograph, but it also gradually weakens paper supports. This is why it is critical to set light levels that are appropriate and considerate of the type of photographs on display. Low intensity illumination of 50-300 lux (5-28 foot-candles) should be used when considering the appropriate light levels for exhibiting photographs. ${ }^{27}$ There are a few ways in which light and UV radiation can be reduced to slow the damage caused by light including using fewer bulbs, placing objects further away from light sources, increasing the angle between light and object, using bulbs of lower wattage, using dimmer switches and intermittent light that will ration the exposure of very sensitive objects to light. Encouraging a public understanding of this practice would be useful because there have been many times when visitors are curious as to why an exhibition space is so dimly lit.

Examples of institutions implementing this initiative into exhibitions include the Cleveland Museum of Art, Nelson-Atkins Museum of Art, and the Museum of Photographic Arts. The Cleveland Museum of Art provides an excellent explanation of the dimly lit exhibition spaces. (Appendix E) This label explains that because most of the work in the respective exhibition is made of paper, light exposure weakens the substrate and can cause fading. Due to this hazard, the light levels are set at appropriate levels for the safe display of the objects. The Nelson-Atkins Museum of Art also uses text to explain lighting levels, but did not state what this

${ }^{27}$ Lavedrine, Bertrand. Photographs of the Past: Process and Preservation. Los Angeles: The Getty Conservation Institute, 2007. 296 
label exactly says. Further, the Museum of Photographic Arts mentions that they have used descriptive text on occasion when lighting conditions are unusually low.

The use of drapes or textile coverings is used to cover such photographs that are timeworn, fragile, and very sensitive to light. The utilization of a drape or curtain allows for preservation to still play a major and important role during exhibition. Drapes assist in the preservation of a photograph such as a daguerreotype by keeping it shielded and protected from unnecessary light exposure. By exposing the object to light only when a visitor is viewing it, allows the photograph to be preserved longer so that it can continue to be enjoyed by various audiences in the future. This is an interesting preservation initiative because in some cases visitors are unsure and confused about what to do when presented with a draped object. Some museums implement a label that reads, "Lift drape to view", but it would be beneficial to include information as to why this object is draped and how it will decrease the damage endured by environmental conditions. A strategy or tool that can be implemented to demonstrate the severity of this to the public could be providing an example of a deteriorated photograph alongside one that is covered by a drape. This would help in asserting understanding for what light damage can result in.

Institutions such as George Eastman House International Museum of Photography and Film, the Nelson-Atkins Museum of Art, the Museum of Photographic Arts and the Metropolitan Museum of Art have implemented the preservation strategy of using drapery or textile coverings to protect objects on display. In addition to using drapery, George Eastman House also provides an explanation in its accompanying text (Appendix E). This label instructs the visitor to lift the curtain and explains that it is shielded due to its fragility and sensitivity to light. This way, the object can be preserved for future audiences. The Nelson-Atkins Museum of Art uses text to 
explain why a photographic object is exhibited behind a curtain, but again, did not state what this text said. Similarly, the Museum of Photographic Arts uses drapery to cover photographic objects, but does not explain why this preservation method is implemented. The Metropolitan Museum of Art states that when they display daguerreotypes, they are shown behind velvet drapes to protect them from unnecessary light exposure. Whether and how that drape is addressed in the label text is completely up to the curator in charge of the exhibition. In some cases there may be no explanation and merely instructions to "lift velvet drape to view". In other instances, the curator might choose to decide to explain why the daguerreotype is covered.

\section{Survey of Best Practice}

\section{Interpretive Museum Signage Pertaining to Photographic Display}

According to a recent survey of literature, effective museum signage includes the physical characteristics of the label itself, its location, and the caption and context of the label. The physical characteristics of a label are vital to its effectiveness because it is these elements (type size, type face, and colour and contrast etc.) that initially attract visitors to them. Type size is one the most important ingredients of a label and is determined by the appropriate viewing distance. The minimum character height for text panels is $5 / 8$ inch.$^{28}$ Further, typeface is another important element of labels. There are three kinds of typeface, including serif, sans serif, and script. For an optimally effective label, it is recommended that fonts in sans serif such as Helvetica, Franklin Gothic or Universe, or typefaces with simple serifs, such as Sabon, Times Roman or New Century Schoolbook be used. ${ }^{29}$ Another important part of label design is the character proportion. It is suggested practice that all lettering and numbers should have a width

\footnotetext{
${ }^{28}$ Standards Manual for Signs and Labels. (Washington, DC: American Association of Museums and the Metropolitan Museum of Art, 1995), 16.

${ }^{29}$ Ibid, 21.
} 
to height ratio of between 3:5 and 1:1. ${ }^{30}$ Letter and line spacing is an important part of the overall effectiveness of a label and a uniform amount of space should be executed between characters and between lines of type for ideal legibility. Colour contrast is in some cases what a visitor notices first and so it is crucial that an appropriate colour combination be established. Ideally, a label should be designed using a light typeface on a dark background or a dark typeface on a light background. ${ }^{31}$ Further, an off-white colour is more optimal than a pure white as it may cause a glare when viewing. It is important to avoid combinations such as blue/green and $\mathrm{red} /$ white. This is because these colours have shorter wavelengths and become harder to perceive, especially for visitors who are older. All labels should use high contrast colours, have a character contrast with the background colour by at least 70 percent, and make use of a label of different colour or shade than the wall it is on - this will assist those with visual impairments. ${ }^{32}$ Text panels or labels work best when executed on a matte, eggshell or other non-glare medium.

In her publication Making Exhibit Labels: A Step-by-Step Guide, Beverly Serrell mentions to consider the caption created by National Geographic as a model to study. Serrell mentions that the first few words of the caption should be in a bold typeface that has darker letters in contrast to the rest of the legend. These words are meant to catch the reader's attention and the bold typeface assists in highlighting colourful, active language. Collectively, the captions highlight the theme of the article, while the first lines contain enough information to express the main idea of the story. The remainder provides additional concepts, ideas, or facts." 33 This

\footnotetext{
${ }^{30}$ Ibid, 22.

${ }^{31}$ Ibid, 26.

32 Ibid, 28.

${ }^{33}$ Serrell, Beverly. Making Exhibit Labels: A Step-by-Step Guide. (Nashville: American Association for State and Local History, 1983), 27.
} 
information is useful because it demonstrates how visual components of the label establish the first impression for, and helps to engage visitors.

The physical location of the label is another important area to explore when considering the implementation of interpretive text because this is a defining factor in the label's accessibility. More often than not, the textual message is in a space much different than a book or newspaper page where the text remains a constant distance from the reader's eyes, and because of this it is important that the message fall within the visitor's normal field of vision. ${ }^{34}$ However, not all visitors are the same height and so labels should be placed at differing heights. In Text in the Exhibition Medium, Andrée Blais states, "like furniture design, exhibition design must from the outset take into account the same constraint, i.e., people come in different sizes, and a common denominator must be sought that satisfies the majority. To simplify matters, we can say that the text should be located on a flat surface facing the visitor, between $1 \mathrm{~m}$ and $2 \mathrm{~m}$ in height. ${ }^{35}$ The Standards Manual for Signs and Labels highlights that text panels should be installed at 48 to 67 inches from the floor at a character height of $5 / 8$ inch ${ }^{36}$ Further, it is important to take into consideration those persons who visit the institution and who face accessibility challenges. As mentioned by the American Association of Museums "in order to ensure proper installation of signs and labels, three factors must be taken into consideration: installation height, viewing angle and intended viewing distance. Ideally, signs and labels should be at a viewer's eye level, in a vertical position, and approachable to within 18 inches. ${ }^{, 37}$ Best practices suggest an effective label is one that is appropriately situated within an exhibition,

\footnotetext{
${ }^{34}$ Blais, Andrée. Text in the Exhibition Medium. Quebec City: Société des Musées Québécois, $1995,239$.

35 Ibid, 239.

${ }^{36}$ Standards Manual for Signs and Labels. (Washington, DC: American Association of Museums and the Metropolitan Museum of Art, 1995), 16.

${ }^{37}$ Ibid, 32.
} 
placed at an appropriate viewing distance, its language is effectively communicated across a variety of audiences and suitable aesthetics are used. However, best practices fail to consider such things as dynamic labels and multimedia. For example, the iPhone can function as a label interface and as a result institutions would only require a Quick Response code (QR code) next to works on display.

Lastly, the caption and context of the label is equally critical in its success - labels aid viewers in the quest to derive meaning from an exhibition. A critical point to consider is that an accessible label or sign is one that can be read and understood by the viewer. ${ }^{38}$ This means that the type size is simple and appropriate for the viewing distance, the characters are sufficiently proportioned, high-contrast colours are utilized for type and background, the consistent use of labels throughout the exhibition, and adequate lighting. In her essay, Writing Exhibition Texts, Helene Baños states "[r]eadability is imperative as the exhibition text is a point of contact between the visitor and the exhibition. If no contact is made, the message cannot be transmitted. Intelligibility is also essential as it helps the visitor retain the message. The information presented must be complete, concise and coherent in order to be accessible. ${ }^{39}$ Because all labels should strive to be appealing and suited to as many visitors as possible, it is important to consider the various types of people that come into museums daily; the casual tourist, the layperson interested in the subject as a hobby, the person whose job is related, the family group visiting to entertain children, the foreign guests with limited English and the new immigrant to the city. ${ }^{40}$

38 Standards Manual for Signs and Labels. (Washington, DC: American Association of Museums and the Metropolitan Museum of Art, 1995), 8.

${ }^{39}$ Blais, Andrée. Text in the Exhibition Medium. Quebec City: Société des Musées Québécois, 1995, 205.

${ }^{40}$ Serrell, Beverly. Exhibit Labels: An Interpretive Approach. (Walnut Creek: AltaMira Press, 1996), 95. 
The targeted audience for labels explaining preservation initiatives engulfs diverse visitor types including those familiar with the current exhibitions, laypersons with an interest in the subject or individuals or groups who stopped in because they thought the museum or institution was worth visiting. However, in regards to a photography exhibition using interpretive signage to explain preservation methods, this would likely attract students of photography, museum professionals, conservation staff or those who have an interest in conservation or preservation, curatorial employees, and people who simply want to know more about what museums do. When planning for an exhibition, it is crucial to think of who our audience will be because this is what helps museum educators, exhibition interpretation staff and curators decide how to write didactic wall text. Since the preservation initiatives mentioned in this paper are similar to interactive displays, they instantly attract visitors to them regardless of their academic background or familiarity with the arts or medium being exhibited. It is important that the label accompanying this type of interactive display aims to provide different access points to its information. One visitor may be drawn to the label for its historic insights, while another visitor may be interested in learning about the display considerations implemented to preserve photographic objects.

One of the intended goals of preservation labeling is audience engagement as it assists in developing relevance to the institution and its work and collections. This is implemented for the people we are ultimately exhibiting for. The individuals visiting a museum exhibiting photography would obviously have some interest in the subject being presented and would certainly be intrigued by preservation on display. The best way to highlight collections care and the most effective way to communicate this with the public is through the use of a text panel or label as this is what develops a connection with object and viewer. Another goal of this type of 
labeling is to highlight preservation concerns, as it is important and beneficial that a public understanding of photographic preservation be established within our audience. This is because we are preserving for the public and our audiences, for the future. The more of an understanding that can be developed amongst the public, the more advocacies for these types of initiatives can be established. This work may be considered important enough to fund raise for or it may simply help situate a visitor within the exhibition or museum as a whole. and assist in their understanding of the chemical composition of some photographic processes. However, museums are presented with a crisis of viewership in times of economic stress. Building relevance goes further by asserting the work of museums, not just exhibition building, but preservation of and for our culture and history. Transparency in labeling can very broadly support museums by investing in their visitors through education.

\section{Conclusion}

Using examples from current practice and recommendations from a survey of literature as a steppingstone, I am proposing four standardized labels for each preservation strategy explored in this paper: the use of timed light-boxes, the use of drapery or textile coverings, the maintenance of low light levels, and the use of facsimiles and surrogates. The intended goal behind creating these labels is to provide standardized text panels to institutions that exhibit photography to not only save the time associated with label making, but to also ensure that preservation on display is effectively explained and communicated with their audiences. The information presented in this research paper, as well as the standardized text panels created to facilitate openness about processes of preservation will be made available to the institutions 
interviewed in this paper, the students and staff associated with Ryerson University's Photographic Preservation \& Collections Management program and George Eastman House International Museum of Photography and Film, and also the general public. It is a hope that these newly created labels will be fully embraced for display and engagement purposes, building more transparent and meaningful engagement experiences for visitors interacting with them.

The implementation of these labels is an effective way to communicate with the public about photographic preservation strategies employed in exhibitions because not only are the preservation displays inviting and attractive, but their written content is appropriate for communicating across a diverse audience. While every label in this study is designed to attract by either asking a lead in question, by using creative typeface or accompanying a unique display apparatus, they are also intended to explain the preservation concerns behind exhibiting photography in hopes that visitors will gain an understanding of the special care required to preserve the medium.

For purposes of limiting this research, no visitor studies were conducted. In future research, it would be interesting to evaluate visitors' responses to this type of signage using surveys or executing gallery observations. This would allow individual institutions to gain insights about whether or not this method of education and information is effective. Visitor feedback would allow specific details about the labels that are either successful or require improvement to be measured. For example, was the label placed in an easy to approach and noticeable location? Did the label assist or deepen their understanding of photographic preservation and why this particular strategy is being implemented? Was the language used to convey the message easy to follow or difficult to understand? 
More contemporary avenues of explaining preservation on display and exhibiting objects include, but are not limited to audio guides, iPad displays and audio-visual television displays. Most institutions still rely on labels to communicate with their audience. The possibility of implementing audio guides or iPad displays that could explain preservation initiatives (or act as one) would layer a new experience; one about facilitating an understanding about preservation work to the already existing experiences. These are excellent avenues for exploring audience education regarding photographic preservation because they are hands-on, direct, and communicate through the use of imagery coupled with text. They even allow for communication with an audience that stems from varied language and cultural groups. Audio guides have been limited in their application, but can be very useful for an audience with varied engagement preferences such as those individuals who are visually impaired, have difficulty with reading, and those people who simply prefer not to read wall text. A museum professional's explanation of the idea of photographic preservation on display may assist the visitor comprehend this notion more effectively than they would have if they were to read the label. Moving forward, the use of iPads is relatively new, however this display itself could be used to exhibit rare or fragile objects as a digital reproduction. It could also be used to demonstrate deterioration over time, while providing information about the object and why it needs to be reproduced in order to prolong its existence. Lastly, audio-visual television displays could and have been useful to explain preservation concerns as a whole. In some cases, museum staff, specifically conservators and curators discuss the implications of not caring for objects adequately and also speaking about works that are on display in the current exhibition. This is effective because it not only provides a visual aid to what is being discusses, but this is amplified with spoken words, which makes it more motivating to appreciate and understand. 


\section{Labels}

Using recommendations provided by a survey of literature and conversations with professionals in the field, the following labels (Appendix A) were created following these suggestions of best practice. In accordance with recommendations for type size and typeface, the

lead-in phrase was set at 20 and the body of the label was set at 12 . Because it was suggested that Helvetica was a sans serif font, it was selected based upon its easy readability. Further, a black on white colour scheme was selected as research demonstrated that high contrasted colour combinations were what visitors first noticed upon entering a gallery space. As mentioned earlier, Beverly Serrell mentions that National Geographic captions were an excellent model to study and this recommendation proved successful during the label construction of this project. The first few words are bolded in contrast to the rest of the label text. The bold lead-in words assist in getting the reader's attention. Lastly, the language used in these labels is intended for any kind of viewer to understand that speaks English as a first language. 


\section{APPENDIX A}

\section{Labels}

Standardized text labels explaining photographic preservation strategies used in exhibitions

IT SURE IS DARK IN HERE! That's because light has the potential to cause fading in the photographs in this gallery and can weaken paper supports. Low light levels are necessary to preserve these works and protect them from further deterioration. This space has been lit at appropriate levels for the safe display of these objects. This allows for visitors to enjoy these works, while still keeping preservation a priority.

\section{WHY IS THIS PHOTOGRAPH DRAPED?}

This photograph is displayed behind a curtain because it is fragile, timeworn and extremely sensitive to light. It is best preserved when exhibited in low light levels and stable climate conditions during display. By exposing this object to light only during visitor observation, it is ensured that it will not undergo any unnecessary deterioration. Please lift the curtain to view this photograph and enjoy the experience of contributing to an important preservation initiative. 
PUSH MY BUTtON, PLEASE! I am a timed light box and my job here in the museum is an important one. Because these photographs are highly light-sensitive, it is critical to maintain their condition. I protect fragile photographs by not only safeguarding them inside of me, but I also protect them by exposing them to light only when my button is pushed. This way when the photographs are not being viewed, they are not undergoing any unnecessary exposure to the harmful rays of light.

\section{THIS IS NOT AN ORIGINAL PHOTOGRAPH.}

Although exhibiting the original photograph would be gratifying, its preservation and care comes first. Because of the delicate condition of the authentic photograph, a reproduction known as a facsimile has been presented in place of the original. This will allow the original photograph to be housed safe in storage, which will protect it from potential light fading associated with exhibiting. This will ensure it is preserved for our future audiences. 


\section{APPENDIX B}

\section{Participating Institutions}

- International Center of Photography

- Cleveland Art Museum

- San Francisco Museum of Modern Art

- J. Paul Getty Museum

- The Phillips Collection

- Carnegie Museum of Art

- Metropolitan Museum of Art

- George Eastman House

- National Gallery of Art

- Nelson-Atkins Museum of Art

- Santa Barbara Museum of Art

- Akron Art Museum

- Harry Ransom Center

- Louisville Collection

- $\quad$ Museum of Photographic Arts

- Museum of Modern Art

- New York Public Library 


\section{Letter to Institutions}

Sample survey letter sent to the Metropolitan Museum of Art

March 22, 2013

Collections Manager

Metropolitan Museum of Art

$10005^{\text {th }}$ Avenue

New York, New York 10028

To Whom It May Concern:

Thank you for being kind enough to participate in my study. I very much appreciate your willingness to help and hope that my work will be a real contribution to our field. As I mentioned in my earlier correspondence my study asks for responses to a brief set of questions.

1. Does the Metropolitan Museum of Art use interpretive text in exhibitions to explain how preservation issues affect the way photographic objects are displayed?

2. If yes, do you use text to explain the following preservation issues and what does your text accompanying such an object say?

a. Why a fragile photographic object is exhibited as a facsimile?

b. Why a photographic object is exhibited behind a curtain?

c. Why a photographic object is displayed in a timed light box?

d. Why light levels are lower than average exhibition spaces?

Are there other issues pertaining to photographic preservation that you explain in interpretive text? If yes, please explain.

3. Do you explain preservation or conservation concerns for objects on display other than photographs? Please explain and provide an example text label.

4. If not, do you believe this method of education and audience engagement would be useful if implemented in your institution? If yes, please explain.

5. If you answered yes to questions no. 2 or no. 3 are you able to provide me with an installation photograph of the objects on display? 
Thank you for taking the time to answer my inquiries and contribute to my thesis research. I will contact you again only if I require further clarification and to share my research with your institution when it is completed.

Best,

Suman Guram

Master's Candidate

Ryerson University/George Eastman House

900 East Avenue

Rochester, New York 14607 


\section{APPENDIX D}

\section{Illustrations}

Examples of various label installations highlighting photography and non-photography related preservation strategies

Figure 1

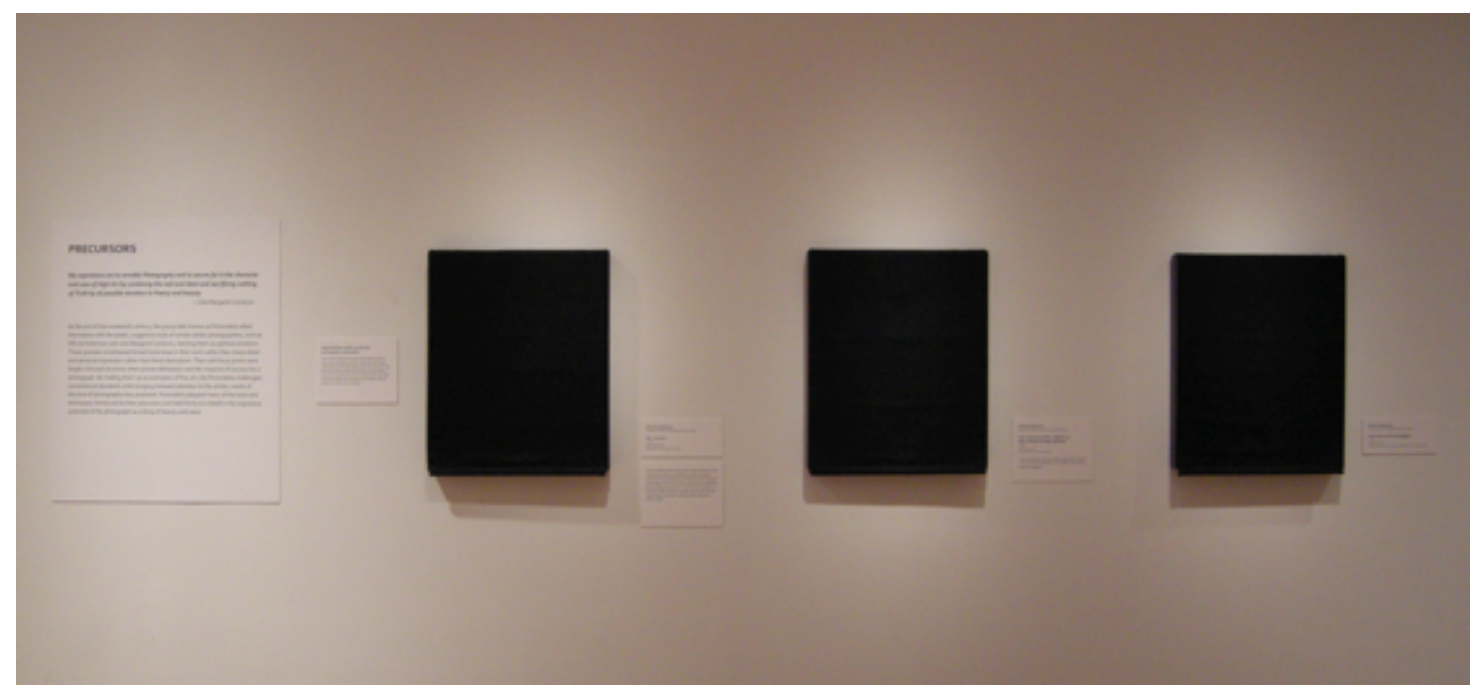

Text label explaining use of drapery, Truth Beauty, The Phillips Collection.

The accompanying label reads:

Please lift the curtain to view the photographs underneath:

The curtains placed over these photographs protect them from the effects of light. These rare and fragile salted paper prints were made over 150 years ago, less than a decade after the invention of the medium, and are best preserved under low light levels and stable climate conditions during storage and display. Please lower the curtain after viewing. 


\section{Figure 2}

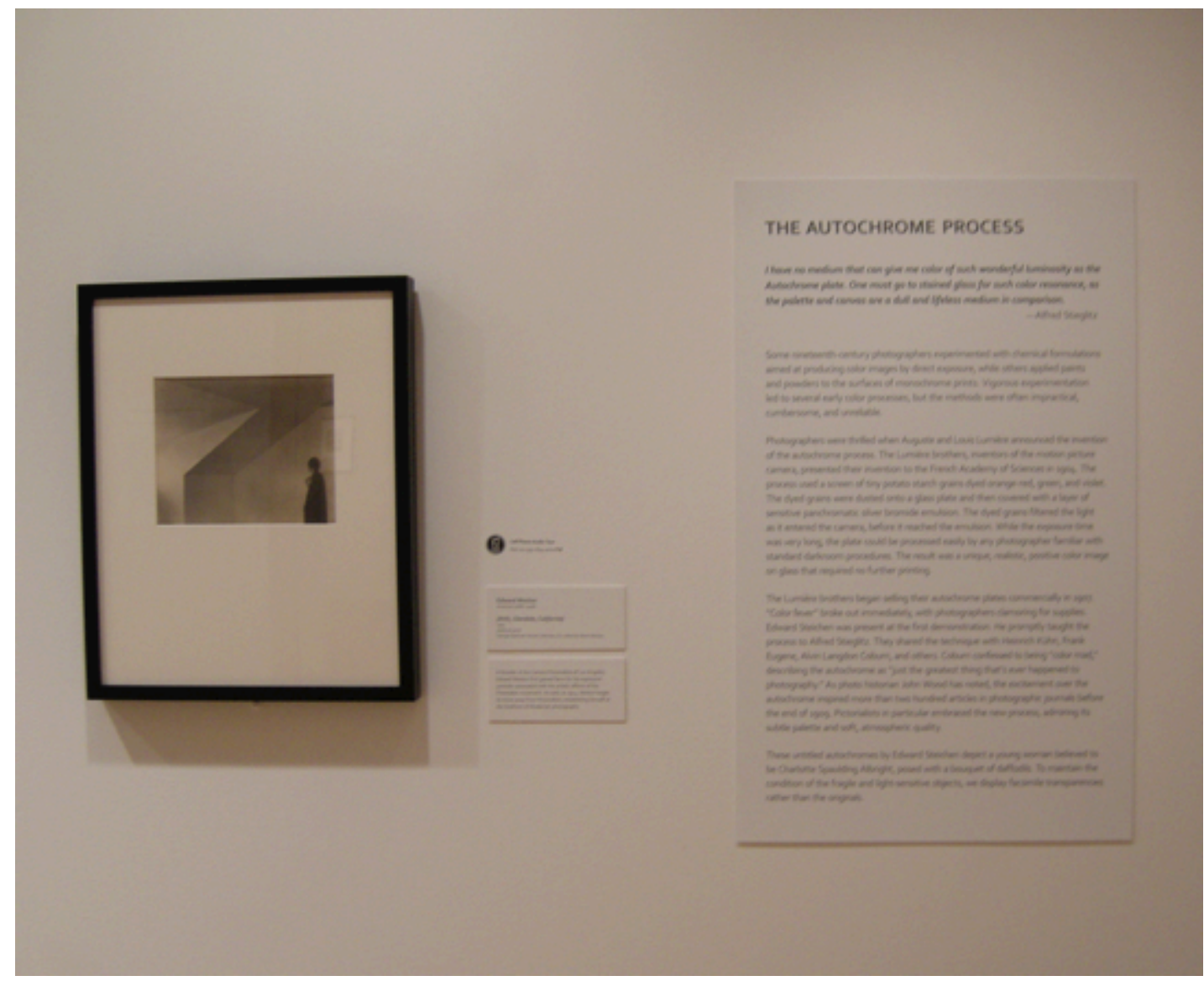

Text label explaining use of facsimiles, Truth Beauty, The Phillips Collection.

The accompanying label reads:

These untitled autochromes by Edward Steichen depict a young woman believed to be Charlotte Spaulding Albright, posed with a bouquet of daffodils. To maintain the condition of the fragile and light-sensitive objects, we display facsimile transparencies rather than the originals. 


\section{Figure 3}

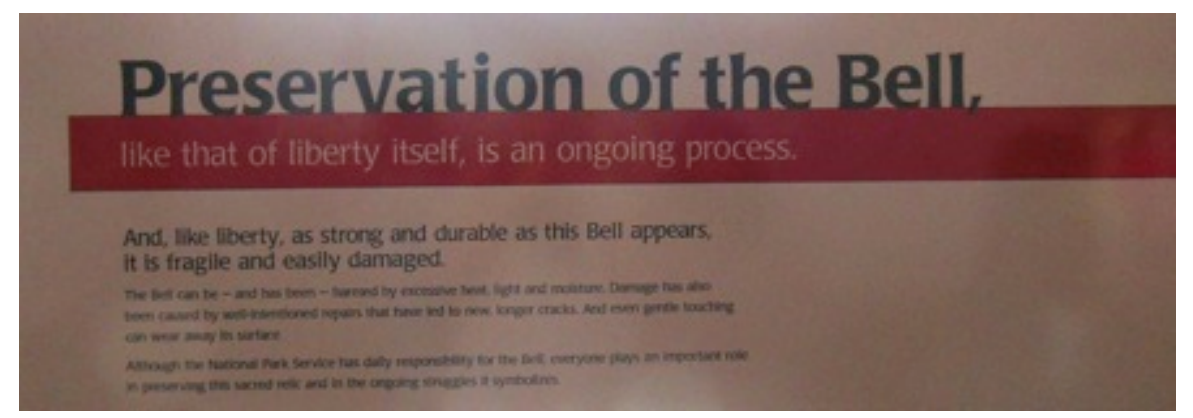

Interpretive label explaining preservation of the Liberty Bell. Liberty Bell, Philadelphia, Pennsylvania. Courtesy of Krista Keller, 2013.

\section{Figure 4}

And, like liberty, as strong and durable as this Bell appears, it is fragile and easily damaged.

The Bell can be - and has been - harmed by excessive heat, light and moisture. Damage has also been caused by well-intentioned repairs that have led to new, longer cracks. And even gentle touching can wear away its surface.

Although the National Park Service has daily responsibility for the Bell, everyone plays an important role in preserving this sacred relic and in the ongoing struggles it symbolizes.

Magnified-Interpretive label explaining preservation of the Liberty Bell. Liberty Bell, Philadelphia, Pennsylvania. Courtesy of Krista Keller, 2013. 


\section{Figure 5}

The boards from the 1944 exhibition, Pictures of Jewish Life in Prewar Poland, are distinguished by numbering in black pen on the bottom left. The boards from the 1945 exhibition, Jewish Life in the Carpathians, are numbered in red at the top center. Although checklists and installation shots from the original YIVO exhibitions have not been found, we are able to reconstruct the two distinct groups from the original black and red numbering schema, and approximate the order in which they were first displayed (only a selection of the boards are shown here).

The original YIVO boards are highly acidic and fragile, and have thus been overmatted for display; one unmatted board from each exhibition is displayed in this case. The 1944 exhibition focused on images of city and town life, divided into twelve groups: "Types," "Trading in the streets of cities and towns," "Old quarters in Kracow, Lublin, Slonim, Vilna, Warsaw," "Home work," "Poverty," "Alleys," "Transportation," "In workshop and factory." "Kheders and yeshivas," "Secular schools," "Children," and "Synagogues, rabbis and prayer." The 1945 exhibition featured images of rural Jewish life, particularly those related to farming and religious observance. Due to the isolation of Jewish communities in the Carpathians, most Eastern European Jewish immigrants would have been unfamiliar with, and therefore particularly curious about, the lifestyle portrayed in these photographs.

Text panel mentioning preservation strategy and issue. CHIM: The Photographs of David Seymour, International Center for Photography, 2013. 


\section{Figure 6}

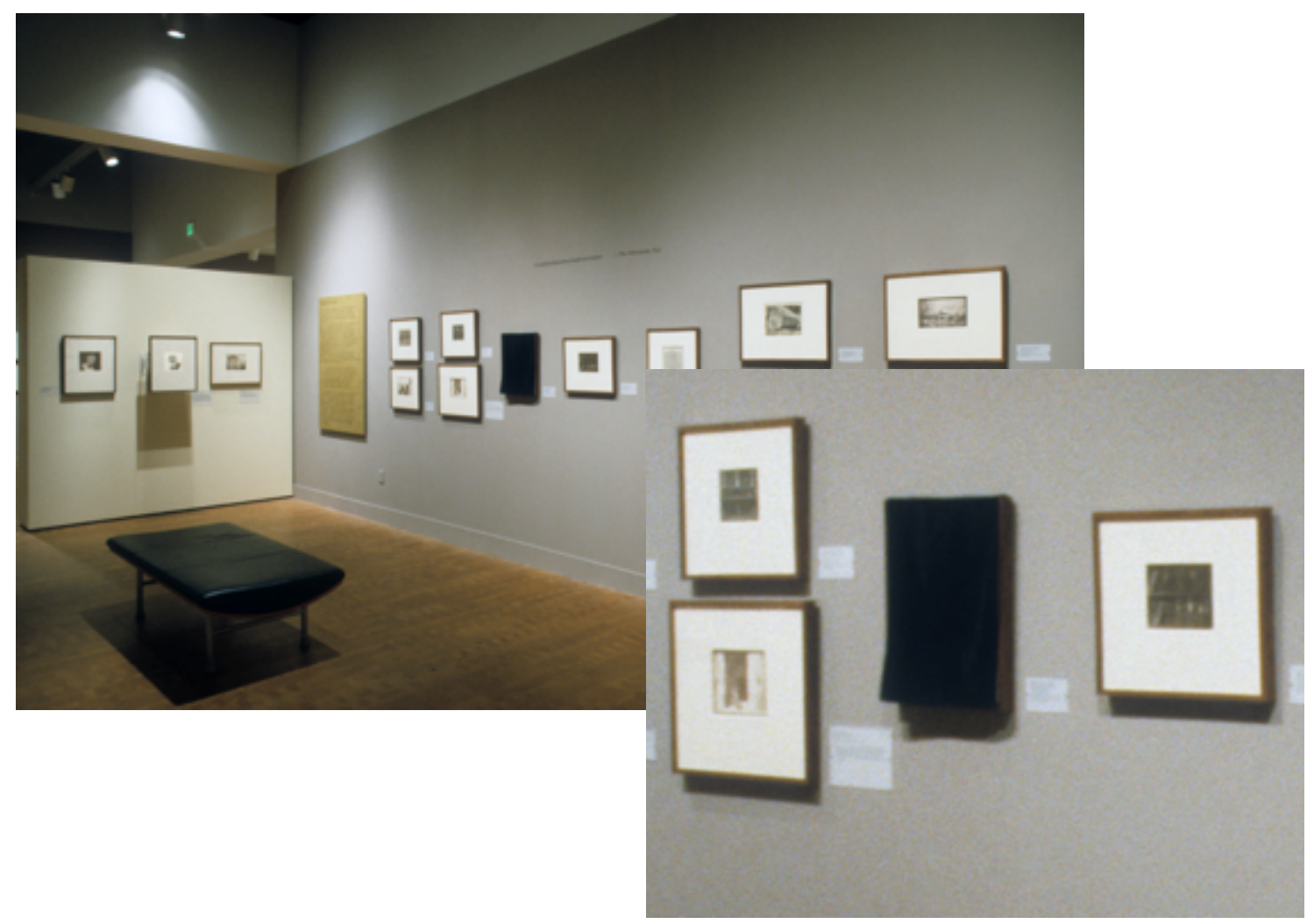

Draped print, First Photographs: William Henry Fox Talbot and the Birth of Photography, Museum of Photographic Arts, San Diego, CA. March 30, 2003-June 15, 2003.

Label reads: Please lift drape to view. 


\section{Examples in Current Practice}

Examples of various label installations highlighting photographic preservation strategies used in current practice

\section{Example 1}

Example of preservation strategy used by George Eastman House International Museum of Photography and Film: Drapery or textile covering

George Eastman House exhibition in Peristyle

Introduction to the Photograph Collection

2008

Curated by Jamie M. Allen

Accompanied a Hill and Adamson salted paper print

Text separate from the wall label Read:

Please lift the curtain...

The photograph under this curtain is old, fragile and very sensitive to light. By keeping it covered except when it is being looked at, we preserve it for future generations to enjoy.

\section{Example 2}

Example of preservation strategy used by the Cleveland Museum of Art: Maintenance of low light levels

\section{WHY THE LIGHTS ARE LOWER IN THIS EXHIBITION...}

All of the works in this exhibition are made of paper. Exposure to light eventually weakens paper and causes other types of gradual deterioration or fading of photographs. Because of this, special restrictions on the light levels are necessary in this exhibition. Light levels are set at accepted museum standards for safe display of the art objects. This may make these galleries seem dimly lit in comparison to other areas of the museum.

The lower light is necessary to help preserve these works for future generations. 


\section{Example 3}

Example of preservation strategy used by George Eastman House International Museum of Photography and Film: Facsimile print

George Eastman House exhibition in Annex Gallery

What We're Collecting Now: The Family Photographed

2009

Curated by students in the PPCM program

Accompanied a selection of facsimiles of family snapshots of Edward Steichen and his family

Text read:

How do a photographer's family snapshots differ from his or her professional work?

Edward Steichen's lengthy career included art, fashion, and military photography as well as curatorial work while Director of Photography at the Museum of Modern Art. These photographs were never intended for public display; however, Steichen's family played a significant role in his life and work. In this collection of photographs of the Steichen family, many were taken in his beloved home in Umpawaug, Connecticut as well as his earlier home in Voulangis, France. Included are images of Steichen, his mother Mary, his first wife Clara, daughters Mary and Kate Rodina, son-in-law Lon Martin, granddaughters Nell and Joan, as well as one of his famed Irish Wolfhounds.

Due to the delicate condition of these photographs, reproductions have been presented in lieu of the originals. This will protect the originals from potential light fading, and will preserve them for future generations. 


\section{Bibliography}

1. Alexander, Edward P., and Mary Alexander. Museums in Motion: An Introduction to the History and Functions of Museums. Lanham: AltaMira Press, 2008.

2. Belcher, Michael. Exhibitions in Museums. (London: Leicester University Press, 1991), 58.

3. Blais, Andrée, ed. Text in the Exhibition Medium. Quebec City: Société des Musées Québécois and Musée de la Civilisation, 1995.

4. Brawne, Michael. The Museum Interior: Temporary and Permanent Display Techniques. (New York: Architectural Book Publishing Company, 1982), 100.

5. Caple, Chris. Conservation Skills: Judgment, Method and Decision Making, (New York: Routledge, 2000).

6. Corr, Susan. Caring for Collections: A Manual of Preventive Conservation. Dublin: The Heritage Council, 2000.

7. Lynn D. Dierking, and John H. Falk, The Museum Experience, (Washington, DC: Whalesback Books, 1992).

8. Excellence and Equity: Education and the Public Dimension of Museums, A Report from the American Association of Museums, 1990.

9. Excellence in Practice: Museum Education Standards and Principles, Developed by the Committee on Education (EdCom), American Association of Museums, 2002.

10. Gilroy, David, and Ian Godfrey, ed. A Practical Guide to the Conservation and Care of Collections. Perth: Western Australian Museum, 1998. 
11. Hooper-Greenhill, Eilean, Museums and the Shaping of Knowledge, (London: Routledge, 1992).

12. Hoveman, Alice R. Alaska State Museum, "Wise Guide." Last modified 2000. Accessed April 3, 2013.

http://docs.google.com/a/geh.org/viewer?a=v\&q=cache:cccP91QGR1MJ:www.museums. state.ak.us/documents/wise_guide.pdf museum signage explaining conservation\&hl=en\&gl=us\&pid=bl\&srcid=ADGEESgTbqIwLps5o3mZH9KgW59KoM m556dmSrztiNUXaSCr0zI8ErWIvfGc2vX1C5joYfchfiPIK7ZGq209LbkLxexIk7n63kL6 H54X1rPg6m7MFQbq63j3T6bDrvi5mlo4NhGU4DQ\&sig=AHIEtbR9wf0neu2N7XRs7G9nBEXw1H8HyA.

13. Keene, Susan. Managing Conservation in Museums, (Oxford: Butterworth Heinemann, 2002).

14. Klobe, Tom. Exhibitions: Concept, Planning and Design. (Washington, DC: The AAM Press of the American Association of Museums, 2012), 34.

15. Lord, Barry, and Gail Dexter Lord, ed. The Manual of Museum Exhibitions. Walnut Creek, CA: AltaMira Press, 2002.

16. Macdonald, Sharon, ed. A Companion to Museum Studies. Malden: Blackwell Publishing, 2006.

17. Meyerowitz, Lisa, ed. National Standards \& Best Practices for U.S. Museums. Washington, DC: American Association of Museums, 2010.

18. National Standards \& Best Practices for U.S. Museums. Washington, DC: American Association of Museums, 2008. 
19. Preventive Conservation in Museums: Video Handbook, Canadian Conservation Institute, Centre de Conservation du Quebec, UQAM

20. Serrell, Beverly. Exhibit Labels: An Interpretive Approach. (Walnut Creek: AltaMira Press, 1996), 9.

21. Serrell, Beverly. Making Exhibit Labels: A Step-by-Step Guide. (Nashville: American Association for State and Local History, 1983), 14.

22. Standards Manual for Signs and Labels. (Washington, DC: American Association of Museums and the Metropolitan Museum of Art, 1995), 8.

23. Stolow, Nathan. Conservation and Exhibitions: Packing, Transport, Storage and Environmental Considerations. (London: Butterworth \& Co., 1987), 5.

24. Talboys, Graeme K. Museum Educator's Handbook, (Hampshire: Gower Publishing Limited, 2000). 